\section{DE DE GRUYTER}

OPEN
Journal of Intercultural Management

Vol. 7, No. 2, June 2015, pp. 151-163

DOI 10.1515/joim-2015-0016

Rasika Sanjeewani Dasanayaka ${ }^{37}$

University of Peradeniya, Sri Lanka

Ravindra Hewa Kuruppuge ${ }^{38}$

Tomas Bata University in Zlin, Czech Republic

\title{
Staff Turnover as a Strategy of Knowledge Management: Empirical Evidence from Information Technology Industry in Sri Lanka
}

\begin{abstract}
Information Technology (IT) industry in Sri Lanka can be considered as one of the fast growing industrial sectors in current competitive, technological oriented and rapidly changing business environment. Generally, IT industry performance depends on knowledge management (KM) in firms in the industry. The concept of staff turnover (ST) has become as more important aspect in the context of knowledge management. As limited research studies are shown in literature about staff turnover and knowledge management in IT industry in Sri Lanka, this research explore the impact of staff turnover on knowledge management in IT companies in Sri Lanka. The survey method has been adopted using structured questionnaire in Likert scale to collect data. Respondents from different job categories and companies for the sample have been selected using stratified sampling method. After descriptive analysis of basic features of respondents of the survey, the causal relationship between staff turnover and knowledge management is analyzed using correlation analysis. The major finding emulating from the study is that there is a positive relationship between high staff turnover and weak knowledge management. Further, the study shows that organizational factors such as managerial style, lack of recognition, lack of competitive compensation system and toxic workplace environment significantly influence employee knowledge management. However, possible learning environment in the firm also directs employee turnover in IT industry in Sri Lanka.

\footnotetext{
${ }^{37}$ sanjeewaned@yahoo.com

${ }^{38}$ kuruppuge@yahoo.com
} 
Key words: Information technology, knowledge management, staff turnover, software industry, Sri Lanka.

\section{Introduction}

Knowledge Management (KM) creates a new working environment where knowledge and experience can easily be shared and also enables information and knowledge to emerge along with a flow to the right people at the right time so that they can act more efficiently and effectively [Akhavan et al. 2009]. An elementary success factor of KM is to have a common understanding of the terms , knowledge management” and ,knowledge sharing” and how they apply to your situation and needs. Some organizations choose not to use these terms at all because they are not accepted within the culture [Koenig and Srikantaiah 2004]. KM is not a single process. It is collaboration of human resources, enterprise organization and culture, as well as the information technology, methods and tools. Furthermore O'Leary et al. [2001] describes a KM system that facilitates creation, access and reuse of knowledge, and its main goals are to promote knowledge growth, communication, preservation and sharing.

Employees' turnover is a much studied phenomenon [Shaw et al. 2001] in human resource management literature. Yet, there is no standard reason as to why people leave organizations. The term "turnover" is defined by Price [1977] as the ratio of the number of organizational members who have left during the period being considered, divided by the average number of people in that organization during that period. Staff turnover (ST) is a major issue in any industry in the world [Long \& Perumal, 2014]. In the IT sector, this can be considered as a common phenomenon. According to Alwis [2008], the problem of ST may arise in any industry as well as in the Public Sector. Therefore, skilled employees leave organizations and eventually knowledge assets will be lost. As a result, it is critical to implement an appropriate procedure to ensure that information and knowledge could be kept in the organization. Organizations invest a lot on their employees in terms of induction and training, developing, maintaining and retaining them in their organization. Therefore, management takes various measures to retain the staff in the organizations.

In Sri Lanka, the Information Technology sector can be considered as one of the major revenue generating sources. At the same time, over the past decades, the software industry in Sri Lanka has developed at a rapid space [CBSL Annual Report 2014]. Nature of the industry is always dynamic and the environment is ever changing. Likewise, a high ST is also visible in the industry. Especially, the software industry thrives on knowledge workers as recruiting qualified and experienced staff has been a focal point to development of IT industry [Herath and Ranasinghe 2011]. However no proper research has been done to identify the impact of ST 
on organizational knowledge management in the Sri Lankan context. At the same time, very few researches have been conducted to investigate matter pertaining to IT sector in Sri Lanka. Hence it is worthwhile to link staff turnover and knowledge management together in an industry where very limited number of researches is conducted. Accordingly research problem of this study remains as in what ways staff turnover effect knowledge management of IT related companies in Sri Lanka.

The following objectives are served as objectives of this study.

- To identify the nature of employees who engage work in IT Industry in Sri Lanka.

- To recognize the organizational units most prone to staff turnover in Sri Lankan IT Industry.

- To analyze the effect of staff turnover on knowledge management and ranking of sub factors of staff turnover in Sri Lankan IT Industry.

Literature review of this article is divided basically into two parts. The first part consists with KM. The second part of the literature review is reserved for ST. The main argument which researchers are trying to build in the literature review is that ST of an organization is the main aspect in case of KM. In the event of building the argument, all sub sections of literature review provide with present knowledge of KM and ST which would support to conceptualize the research problem of this study.

$\mathrm{KM}$ is not a single process. It is of course is a collaboration of human resources, enterprise organizational culture, information technology, methods and tools that support to organization to run their functions smoothly. Furthermore O'Leary et al. [2001] describes a KM system that facilitates creation, access and reuse of knowledge, and its main goals are to promote knowledge growth, communication, preservation and sharing. According to Montequin et al. [2006], making the transition becoming a firm that manages efficiently in all aspects of knowledge is not a trivial step, even less when talking about small and medium-sized enterprises (SMEs). Knowledge and KM are vital areas for most organizations nowadays, especially those that are knowledge intensive. Firms should develop the right circumstances to stimulate the development of knowledge. Implementing KM means something more than implementing a set of IT tools: it involves changes in the organizational structure, process and culture. The first step to change from a traditional company into a KM is to be aware of the knowledge of the organization. In addition to that, Yu-Chung et al. [2005] explains Knowledge as not easily measured or audited, so organizations must manage knowledge effectively in order to take full advantage of the skills and experience inherent in their systems and structures as well as the tacit knowledge belonging to the employees of the firm. KM can more effectively integrate and administer a firm's information technology base and assist in the development of a systematized information model. 
When key factors of $\mathrm{KM}$ is considered different views researchers can be recognized. Bixler [2002] states that there are four pillars to support enterprisewide KM initiatives: leadership, organization, technology and learning. Managers develop business and operational strategies to survive and position for success in today's changing environment, so leadership is needed. Those strategies determine vision, and must align $\mathrm{KM}$ with business tactics to drive the value of $\mathrm{KM}$ throughout the enterprise. For an organization to succeed, the value of knowledge creation and collaboration should be intervened throughout the enterprise. Operational processes must be aligned with the KM framework and strategy, including all performance metrics and objectives. Technology enables and provides the entire infrastructure and tools to support KM within the enterprise. Organization learning must be addressed with approaches such as increasing internal communications, promoting cross-functional teams and creating a learning community.

Four pillars of KM help to understand the factors with effect to KM. According to Stankosky and Calabrese [2005] leadership deals with the environmental, strategic and enterprise level decision making processes involving the values, objectives, knowledge requirements, knowledge sources, prioritizations and resource allocation of the organization's knowledge assets. It stresses the need for integrative management principles and techniques, primarily based on systems thinking approaches. Further the organization deals with the operational aspects of knowledge assets, including functions, processes, formal and informal organizational structures, control, measures, process improvement and business process reengineering. The adoption of technology deals with the various information technologies peculiar to supporting and/or enabling KM strategies and operations. That is one way used which relates to technologies that support the collaboration and codification of KM. Finally, learning deals with organizational behavioral aspects and social engineering. The learning pillar focuses on the principles and practices to ensure that individuals collaborate and share knowledge to the maximum. Emphasis is given to identifying and applying the attributes necessary for a "learning organization". According to Stankosky [2005], all four pillars must be balanced in order to avoid failing the whole system.

Turnover is defined differently in previous studies. One of the famous definition is "individual movement across the membership boundary of an Organization" [Price, 2001; Thwala et al., 2012]. Interestingly, a large number of studies in this field use turnover intentions of employees as a proxy for actual turnover of employees, given that they are the only variables that consistently and directly predict actual turnover [e.g., Hancock et al. 2013; Holtom et al. 2008]. Several meta-analyses have emphasized on managerial approaches to employee retention, focusing the appropriateness of positive organizational support, job satisfaction, and perceptions of external employment opportunities on turnover intentions [Berry, Lelchook \& Clark 2011; Hancock et al. 2013, Long \& Perumal 2014] explained that human 
resource practices are more important than any other reason in case of ST in present day organization. According to their research findings human resources practices like recruitment practices, managerial style, lack of recognition, lack of competitive compensation system and toxic workplace environment have become top priorities of employees in case of turnover intention of their job.

Literature shows that some attempts to link the concepts of KM and ST. According to Foster [1999] the benefits of a KM programme, initiative, strategy or system can be many and varied, and cost justification may be difficult. More interestingly the survey of KPMG's study [cited in Penelope et al. 2001, p. 24] stated that 'the ability to leverage the intellectual capital of the organization can reap numerous benefits' and it lay emphasis on improved staff morale (making a search for, and access to information easier and quicker, thus permitting more time for innovation, higher quality work, and more accurate decisions often evidenced by a reduction in staff turnover or easier attraction of high-caliber recruits) which can be seen as a more important factor in the sense of KM. According to Stovel et al. [2002] human resource managers are effectively managing the people in their organizations through training and development, performance reviews, and the effective management of fluctuating workforce demands. Moreover there is a need for greater attention to be paid to the leveraging of human capital that exists within their knowledge-intensive workforce. In addition, research findings strongly suggest the need to increase KM behaviors such as the valuation and codification of organizational knowledge assets. Further Akhavan et al. [2006] stated that the benefit and importance of KM is clear to every organization and nowadays, many companies search for the main reasons and factors for being successful in KM system design and implementation through their organization.

Conceptualization (figure 1) of the study was developed based on the literature review above.

Figure 1. Conceptualization

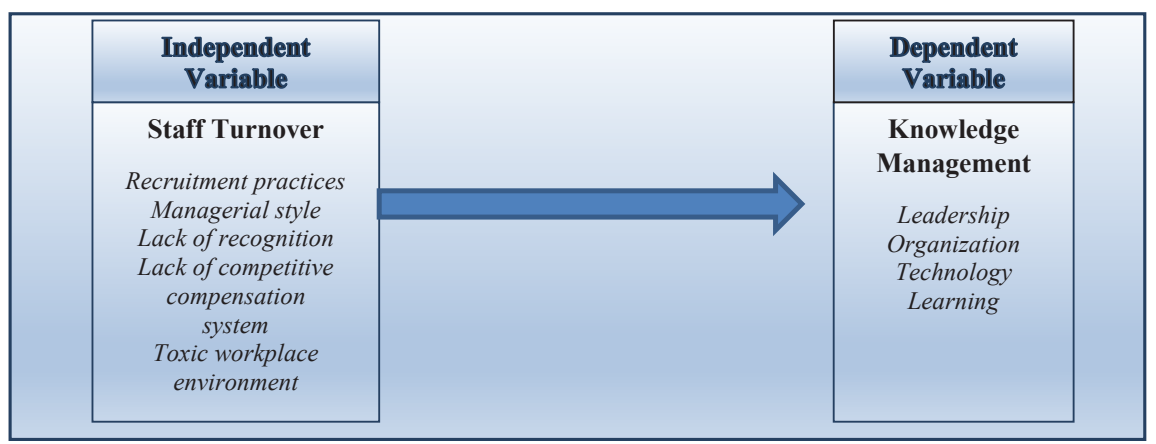

Source: developed by the researcher based on literature. 
The following hypothesis can be drawn from the conceptual framework.

Ho: Null Hypothesis

There is no strong positive relationship between high staff turnover and weak knowledge management.

H1: Alternative Hypothesis

There is a strong positive relationship between high staff turnover and weak knowledge management.

The operationalization of the study is carried out based on the conceptual framework. Ultimately, operationalization is lead to test the hypothesis of the study.

\section{Material and Methods}

This study has focused on finding out the impact of ST on KM in companies in IT industry in Sri Lanka. According to Sri Lanka Information Communication Technology Association (SLICTA), the current total workforce involved in IT sector is around 60,000 in which 29,000 workers are directly involved in jobs in Sri Lanka. In addition, according to IT work force categories can be mainly divided into thirteen job sectors such as Database Administration and Development, Digital Media and Animation, Systems and Network Administration, Project and Program Management, Technical Support, Web Development, Solutions and Technical Architect, Business Analysis and Systems Integration, Programming and Software Engineering, Testing/Quality Assurance, Management Information Systems / IT Management, Technical Writing and Sales and Marketing.

The sample of this survey was designed based on the above information. The primary data was collected from randomly selected 34 software related companies and their employees which were categorized in 13 different jobs. 34 software related companies were selected using simple random sampling technique from the list of IT related companies given by the SLICTA. A questionnaire which covered all measurements in the conceptualization was sent to employees in different job categories. Those employees were selected based on stratified random sampling technique. The questionnaire was developed based on all constructs, indicators of variables of conceptualization. The questions were developed in five point Likert scale. Mainly, received responses from different mode of data collection can be seen by following table 1. Finally, this survey covered 119 responses from different companies from different job positions related to IT Companies.

Table 1. Mode of data collection and response rate

\begin{tabular}{|l|l|l|l|l|}
\hline Method & $\begin{array}{l}\text { No of questionnaires } \\
\text { delivered }\end{array}$ & Percentages of delivery & Received & Return Rate \\
\hline E-mail & 130 & $24.5 \%$ & 28 & $23.5 \%$ \\
\hline Printed copies & 150 & $28.3 \%$ & 39 & $32.7 \%$ \\
\hline
\end{tabular}




\begin{tabular}{|l|l|l|l|l|}
\hline $\begin{array}{l}\text { Online invitations } \\
\text { (survey) }\end{array}$ & 250 & $47.1 \%$ & 52 & $43.6 \%$ \\
\hline Rejections on receipt & & & $(20)$ & \\
\hline Total & 530 & $100 \%$ & 119 & $100 \%$ \\
\hline
\end{tabular}

Source: developed by the researcher.

The fieldwork included analysis of secondary documentary sources in each organization to analyze and conclude the study. Documents were collected from the organizations' resource center, libraries of various universities, company reports, company newsletter and other printed materials (e.g. newspaper cuttings, journals, textbooks, conference reports, articles) that were made available for the purpose of the research.

The correlation (Pearson) analysis is used as the main data analysis model to test the hypothesis. The relationship of independent and dependent variables were identified in a function. The following mathematical array shows the development of correlation model for this study. The correlation between the above dimensions, variables and the concepts can be explained as in the equation below. When considering the variable ST passion towards staff turnover, Ave_RP, Ave_MS, Ave_R, Ave_CCS and Ave_TWE satisfies ST. Therefore, mathematical development of function can be stated as below.

$$
\begin{aligned}
& \mathrm{ST}=\text { Ave_RP }+ \text { Ave_MS }+ \text { Ave_R }+ \text { Ave_CCS }+ \text { Ave_TWE } \\
& \text { Ave_ST }=(\text { Ave_RP }+ \text { Ave_MS }+ \text { Ave_R }+ \text { Ave_CCS }+ \text { Ave_TWE }) / 5 \\
& \text { Ave_KM }=(\text { Ave_L }+ \text { Ave_O }+ \text { Ave_T }+ \text { Ave_LEA }) / 4
\end{aligned}
$$

\section{Data analysis and results}

\section{Descriptive analysis of primary data in the sample}

Initially, responses and individuals of the sample were analyzed descriptively. It has been found in the sample of data that nearly $41.2 \%$ respondents are male and $58.8 \%$ of them are female. Respondent's ages are distributed in the range of 18 to 55 . The highest group of respondents is reported (73.1\%) in the age group of $21-34$ years. This is significant since it shows that most of the respondents are young and they can be considered as catalyst in the development of the industry. The level of education in the Sri Lankan IT work force has more bachelors compared to other educational categories. That is an average of $64.7 \%$, the second highest educational qualification is postgraduate degree. Two participants have obtained professional qualification in Microsoft product qualifications. The analysis further shows a percentage of breakdown of the respondent's line of department. The highest number of employee category who participated in our survey is Programming 
and Software Developers. It reports that 33 participants from that employee category covering $27.7 \%$ of the sample. Another $11.8 \%$ is from software Quality Assurance. Two persons represent from IT support and Business Analysis and Systems Integrations. Only nine respondents are from the Project and the Program Management field. The analysis of work experiences of respondents reports that $39 \%$ of respondents have more than 5 years of experience in the industry. And, some respondents who are working in the same organization more than 10 years are around $9.2 \% .25 .2 \%$ of respondents have continued their service without breaking in the same organization at least 3 to 5 years. Employees continuous service less than 2 year period in the same organization reports $27.7 \%$ o. Following figure 2 indicates respondent's work experience in the industry.

Figure 2. Respondent's years of working in the firm

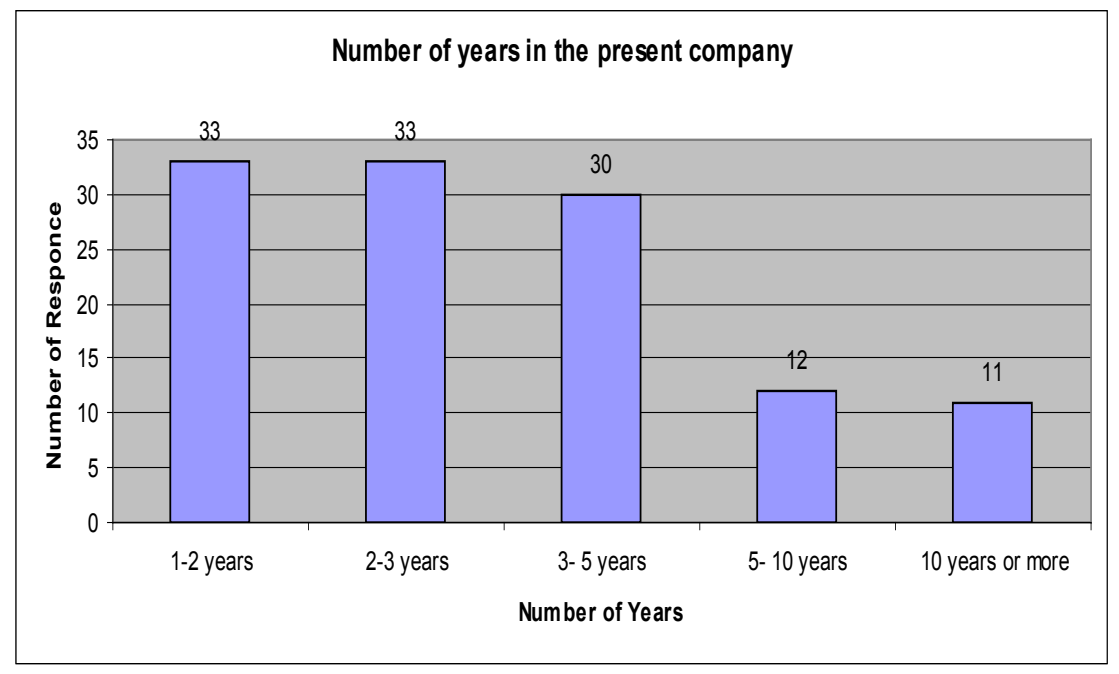

Source: developed by the researcher.

The rapid growth of IT industry related product and services, knowledge expertise has a major role in Sri Lankan IT industry. As figure 2 illustrates, as the salient feature of the graph, only eleven respondents have continued working for the same organization for more than 10 years. And only another twelve respondents have been successful in rendering their cooperation to the same organization more than five years. 
Figure 3. Respondent's work experience in the IT industry

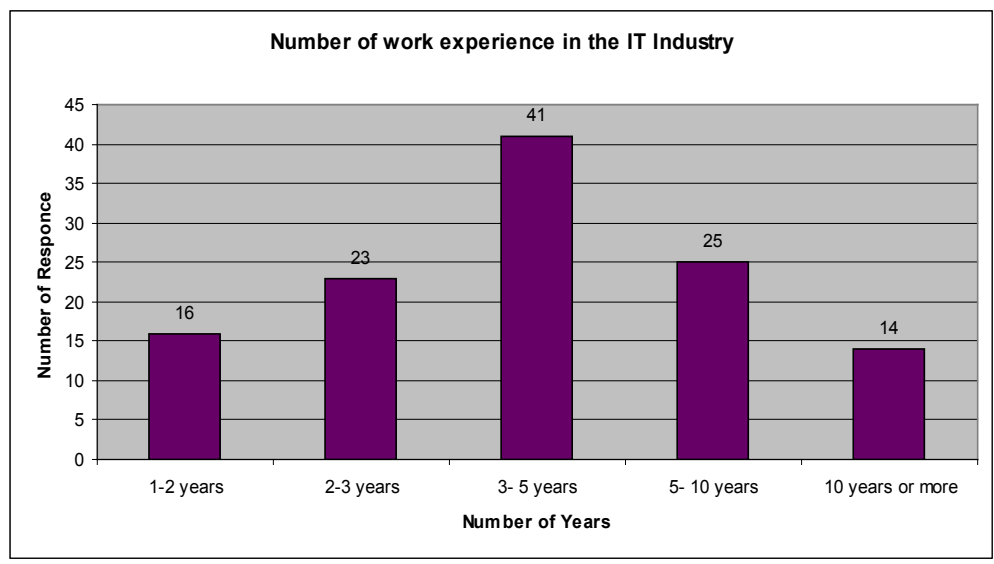

Source: developed by the researcher.

The growth of any industry allow workers to move among firms in the industry. It is a common problem in a modern world due to different choices of employees. Figure 3 shows that the respondent's work experiences in the industry were. Forty-one respondents who represent the highest number of work experience in the industry reports only 3 to 5 years. Only Fourteen respondents have been working more than ten years in the industry. This analysis directs that experienced employees are not retaining and moving from IT industry to another industry. This would create a negative impact to IT business as lack of experienced employees in any industry makes drawbacks to relevant business.

\section{Statistical analysis of indicators and hypotheses testing}

In the analysis of data collected from survey, the test for goodness of data is performed for both independent and dependent variables. The inter-item consistency reliability or the Cronbach's Alpha reliability coefficient of each independent and the dependent variables was obtained to measure the goodness of data. The Cronbach's Alpha received was between $0.7-0.8$ ranges and the internal consistency reliability of the measures used in this study can be considered to be good.

Comparing the two concepts of the study, staff turnover (ST) and the knowledge management $(\mathrm{KM})$ have considerably justifiable by mean values. It implies that the responses for independent variable are closer to the middle end (neither agree nor disagree). However the mean value responses for the dependent variable dimensions of Organization (Ave_Organization) and the independent variable Toxic Workplace Environment (Ave_Toxic_Work_Env) place around 3.7. It implies that the responses for two dimensions are closer to the top end (Agree). Further, the results show that the standard deviations of dimensions are quite small and therefore the responses for ST and KM lie closer to the mean. 
Data analysis of responses indicates interesting summary that mean and standard deviation of agreement in their responses in each statement. Roughly 74\% (Agree and strongly agree) of the responders concern their organizations have a sense of community. The mean value was 4.01 and standard deviation as 0.987 and the author sets point 4 as agreed level. This clearly depicts that the Sri Lankan software organizations have a sense of community. As a result of sense of community in organization which is very important to attract people to industry, it would create refocusing people on shared values, and create an environment of support in which employees are fully engaged.

Another interesting figure is reported the mean value of 4.00 and standard deviation of 0.966 for the question 'whether the organization culture encouraged me to work'. Approximately $82 \%$ respondents are expressed that either they agree or strongly agree. It is made to a conclusion that organization culture plays a major role in case of turn over intention of employee in the IT sector.

The third highest mean value is 3.88 (1.001) is reported by organization "learning culture" among the employees. It shows that it is important to establish the perceptions of staff toward the dimension of culture in enhancing organizational learning readiness. In addition, managers of software industry should find the results of this study useful in designing work shifts intended to promote organizational learning practices.

\section{Hypothesis Testing}

As stated at the beginning of the chapter the research project has been designed to test one hypothesis. The hypotheses are tested using a statistical analysis techniques; Pearson correlation. Each hypothesis has been broken down to null hypothesis and alternative hypothesis as shown above to test them easily.

Table 2. Correlation of staff turnover and knowledge management

\begin{tabular}{|c|c|c|c|}
\hline \multicolumn{4}{|c|}{ Correlation analysis } \\
\hline & & $\begin{array}{l}\text { Knowledge } \\
\text { management }\end{array}$ & Staff turnover \\
\hline \multirow[t]{3}{*}{$\begin{array}{l}\text { Knowledge } \\
\text { management }\end{array}$} & $\begin{array}{l}\text { Pearson } \\
\text { Correlation }\end{array}$ & 1 & $0.233^{*}$ \\
\hline & Sig. (2-tailed) & & 0.011 \\
\hline & $\mathrm{N}$ & 119 & 119 \\
\hline \multirow[t]{3}{*}{ Staff turnover } & $\begin{array}{l}\text { Pearson } \\
\text { Correlation }\end{array}$ & $0.233^{*}$ & 1 \\
\hline & Sig. (2-tailed) & 0.011 & \\
\hline & $\mathrm{N}$ & 119 & 119 \\
\hline \multicolumn{3}{|c|}{ *. Correlation is significant at the 0.05 level (2- } & Tailed). \\
\hline
\end{tabular}

Source: developed by the researcher based on the survey results. 
As shown in table 2 , as the significance level is less than 0.05 , which is shown 0.011, the researcher can reject the null hypothesis. Therefore, the outcome of the correlation analysis indicate that there is a strong positive relationship between high staff turnover and weak knowledge management. In the other way, alternative hypothesis is accepted reviewing that positive relationship between high staff turnover and weak knowledge management. But according to the results of correlation, it is clear that it is not strong positive relationship.

\section{Discussion and conclusion}

This study focuses to reveal the relationship of ST and KM. More precisely, it reveals the impact of staff turnover as a strategy of knowledge management in IT Industry in Sri Lanka. Three objectives, namely, to identify nature of employees who engage in Sri Lankan IT Industry, to recognize the organizational units most prone to staff turnover in Sri Lankan IT Industry and to analyze the effect of staff turnover on knowledge management and ranking of sub factors of staff turnover in Sri Lankan IT Industry, were achieved by this study. First and the second objectives of the study were achieved in the descriptive analysis of data. The co-relation analysis was used to achieve the third objective.

The co-relation analysis shows that the positive relationship between staff turnover and weak knowledge management. It further rejects the null hypothesis of the study recommending firms in the IT sector to concentrate more on keeping IT staff in the firm in order to maintain better knowledge management in the firm. This is further specified in the descriptive analysis of different job categories in IT sector in the analysis of second objective. The analysis further shows that how employees more prone to leave the firm in line with their experience in the industry. As a whole, in order to better knowledge management, a pool of experienced employees in the industry is recommended by the study. Further, the study shows that organizational factors such as managerial style, lack of recognition, lack of competitive compensation system and toxic workplace environment significantly influenced employee knowledge management in software industry. At the same time, the analysis shows that if the person who is doing the same job role over a long period in the same organization in the IT industry, then that person becomes a prized asset to the organization. Those people's deep domain knowledge is highly important to organization performance as well as sustainability of organization. According to the analysis this is further supported by creating learning culture in IT related companies in the IT Industry. 


\section{Bibliography}

Akhavan P., Hosnavi R., Sanjaghi M.E. (2009), Identification of knowledge management critical success factors in Iranian academic research centers, "Education Business and Society: Contemporary Middle Eastern Issues”, Emerald Group Publishing Limited. Vol. 2, No. 4, pp. 276-288.

Akhavan P., Jafari M., Fathian M. (2006), Critical success factors of knowledge management systems: a multi case analysis, "European Business Review”, Emerald Group Publishing, Vol. 18 No. 2, pp. 97-113.

Alwis L.S.P (2008), Knowledge management and organization performance, Department of Computer Science \& Engineering, (MBA unpublished thesis), University of Moratuwa Sri Lanka.

Annual Report (2014), Central Bank of Sri Lanka, Colombo, Sri Lanka.

Berry C.M., Lelchook A.M., Clark M.A. (2012), A meta-analysis of the interrelationships between employee lateness, absenteeism, and turnover: Implications for models of withdrawal behavior, "Journal of Organizational Behavior", 33, 678-699.

Bixler C.H. (2002), Applying the fourpillars of knowledge management, "KM World", Vol.11, No.1.

Foster F. (1999), Justifying knowledge management investments, Knowledge and Process Management, "Emerald Group Publishing Limited" Vol. 6, No. 3, pp. 154-157.

Hancock J.I., Allen D.G., Bosco F.A., McDaniel K.R., Pierce C.A. (2013), Meta-Analytic Review of Employee Turnover as a Predictor of Firm Performance, "Journal of Management", 573-603.

Herath H.M.T.S, Ranasinghe A. (2011), Labour Market Prospects for Business Graduates in Sri Lanka, "International Journal of Social Science and Humanity", Vol. 1, No. 1, pp 26-30.

Holtom B., Mitchell T., Lee T., Eberly M. (2008), Turnover and Retention Research: A Glance at the Past, a Closer Review of the Present, and a Venture into the Future, "Academy of Management Annals", 2(1), 231-274.

Koenig E.D., Srikantaiah T.K. (2004), Knowledge Management Lessons Learned - What works and what doesn't, "Information Today", Vol. 2, pp. 55-69.

Long C.S., Perumal P. (2014), Examining the impact of human resource management practices on employees' turnover intention, "International Journal of Business and Society”, 15(1), 111-126. Retrieved from http://search.proquest.com/docview/1514821371 ?accountid $=15518$

Long C.S., Perumal P. (2014), Examining the impact of human resource management practices on employees' turnover intention, "International Journal of Business and Society", vol 15, no. 1, pp. 111-126.

Montequin V.R., Fernández, F.O., Cabal V.A., Gutierrez N.R. (2006), An integrated framework for intellectual capital measurement and knowledge management implementation in small and mediumsized enterprises, "Journal of Information Science”, Vol. 32, No.6, pp. 525-538.

O’Leary D.E., Studer R. (2001), Knowledge Management: An Interdisciplinary Approach, "IEEE Intelligent Systems", January/February, Vol. 16, No. 1. 
Penelope Y., Bawden D. (2001), Managing the paradox: the valuation of knowledge and knowledge management, "Journal of information science", Vol. 28, No 1, pp. 19-29.

Price J.L. (2001), Reflections on the Determinants of Voluntary Turnover, "International Journal of Manpower", 22, 600-624.

Price J.L (1977), The study of turnover, 1st edition, Iowa state university press, pp. 10-25.

Shaw J.D., Dess G.D. (2001), Voluntary turnover, social capital, and organizational performance, "Academic Management", Vol. 26 No.3, pp. 446-56.

Stankosky M.A. (2005), Advances in Knowledge Management: University Research toward an Academic Discipline, Creating the Discipline of Knowledge Management, Elsever Butterworth-Heinemann, pp.1-15.

Stovel M., Bontis N. (2002), Knowledge management - friend or foe?, "Journal of Intellectual Capital", Vol.3, No.3, pp. 303-322.

Thwala D.W., Ajagbe M.A., Choi S.L., Bilau A.A., Enegbuma W.I. (2012), Sudanese Small and Medium Sized Construction Firms: An Empirical Survey of Job Turnover, "Basic Applied Social Research (JBASR)", 2(8), 7414-7420.

Thwala D.W., Ajagbe A.M., Enegbuma W.I., Bilau A.A., Long C.S. (2012), Sudanese small and Medium Sized Construction Firms: An Empirical Survey of Job Turnover, "Journal of Basic, Applied Scientific Research (JBASR)", 2(8), pp. 7414-7420.

Yu-Chung H., Shi-Ming H., Quo-Pin L., Mei-Ling-Tsai (2005), Critical factors in adopting a knowledge management system for the pharmaceutical industry, "Industrial Management \& Data Systems", Vol. 105, No 2, pp. 164-183. 